\title{
Surface modification of electrospun cellulose acetate nanofibers via RAFT polymerization for DNA adsorption
}

\author{
Serkan Demirci ${ }^{\mathrm{a}, \mathrm{c}, *}$, Asli Celebioglu ${ }^{\mathrm{a}, \mathrm{b}}$, Tamer Uyar ${ }^{\mathrm{a}, \mathrm{b}, * *}$ \\ a UNAM-National Nanotechnology Research Center, Bilkent University, 06800 Ankara, Turkey \\ ${ }^{\mathrm{b}}$ Institute of Materials Science and Nanotechnology, Bilkent University, 06800 Ankara, Turkey \\ c Department of Chemistry, Faculty of Arts and Sciences, Amasya University, 05100 Amasya, Turkey
}

\section{A R T I C L E I N F O}

\section{Article history:}

Received 13 January 2014

Received in revised form 22 June 2014

Accepted 23 June 2014

Available online 11 July 2014

\section{Keywords:}

Electrospinning

Cellulose acetate

Nanofiber

Surface modification

RAFT polymerization

DNA adsorption

\begin{abstract}
A B S T R A C T
We report on a facile and robust method by which surface of electrospun cellulose acetate (CA) nanofibers can be chemically modified with cationic polymer brushes for DNA adsorption. The surface of CA nanofibers was functionalized by growing poly[(ar-vinylbenzyl)trimethylammonium chloride)] [poly(VBTAC)] brushes through a multi-step chemical sequence that ensures retention of mechanically robust nanofibers. Initially, the surface of the CA nanofibers was modified with RAFT chain transfer agent. Poly(VBTAC) brushes were then prepared via RAFT-mediated polymerization from the nanofiber surface. DNA adsorption capacity of CA nanofibrous web surface functionalized with cationic poly(VBTAC) brushes was demonstrated. The reusability of these webs was investigated by measuring the adsorption capacity for target DNA in a cyclic manner. In brief, CA nanofibers surface-modified with cationic polymer brushes can be suitable as membrane materials for filtration, purification, and/or separation processes for DNA.
\end{abstract}

(c) 2014 Elsevier Ltd. All rights reserved.

\section{Introduction}

Electrospinning technique has recently received great attention since this versatile technique enables the production of multifunctional nanofiber/nanowebs from a wide range variety of materials including polymers, blends, alloys, composites, ceramics, metals etc. (Agarwal, Greiner, \& Wendorff, 2013; Sahay et al., 2012; Wendorff, Agarwal, \& Greiner, 2012). The electrospun nanofibers and their nanowebs have distinct characteristic such as very high surface area to volume ratio, nanoscale porous morphology and the diverse surface functionalities are also possible (Agarwal et al., 2013; Kayaci, Ozgit-Akgun, Biyikli, \& Uyar, 2013; Lu \& Hsieh, 2010; Muller, Rambo, Porto, Schreiner, \& Barra, 2013; Sahay et al., 2012; Uyar, Havelund, Hacaloglu, Besenbacher, \& Kingshott, 2010; Wendorff et al., 2012). These properties of electrospun nanofibers

\footnotetext{
* Corresponding author at: UNAM-National Nanotechnology Research Center, Bilkent University, 06800 Ankara, Turkey. Tel.: +90 3582421614; fax: +903582421616 .

** Corresponding author at: UNAM-National Nanotechnology Research Center, Bilkent University, 06800 Ankara, Turkey. Tel.: +90 3122903571; fax: +903122664365.

E-mail addresses: srkndemirci@gmail.com, serkan.demirci@amasya.edu.tr (S. Demirci),uyar@unam.bilkent.edu.tr, tamer@unam.bilkent.edu.tr, tameruyar@gmail.com (T. Uyar).
}

make them good candidates as affinity membranes for filtration, purification and separation processes (Ma, Kotaki, \& Ramakrishna, 2005; Zhu, Yang, \& Sun, 2011). Surface modification of electrospun nanofibers with specific functional groups is of great interest due to their potential application in filtration/separation, detection and controlled drug release (Chigome, Darko, \& Torto, 2011; Fu, Xu, Yao, Li, \& Kang, 2009a; Kampalanonwat \& Supaphol, 2010; Mahanta \& Valiyaveettil, 2011; Wang et al., 2012; Yao, Xu, Lin, \& Fu, 2010). Particularly, polymer functionalized nanofibers that can be obtained via living radical polymerization (LRP) techniques may have a high adsorption capacity and strong binding specificity due to their free active groups on nanofiber surfaces (Chigome et al., 2011; Yao et al., 2010).

LRP reveal advantages because they can control the architecture, molecular weight and molecular weight distribution in comparison with the conventional radical polymerization, due to minimal termination reactions resulting in polymer chains with "living" end groups (Coessen, Pintauer, \& Matyjaszewski, 2001; Fu et al., 2009a, 2009b; Matyjaszewski, 2012; Pyun \& Matyjaszewski, 2001). Several LRP techniques have been reported for preparation polymer functionalized surfaces, such as nitroxide-mediated radical polymerization (Bian \& Cunningham, 2006; Cimen \& Caykara, 2012), atom transfer radical polymerization (Bai, Zhang, Cheng, \& Zhu, 2012; Bian \& Cunningham, 2006; Turan, Demirci, \& Caykara, 2010), reversible addition-fragmentation chain transfer (RAFT) 
polymerization (Demirci \& Caykara, 2012; Gurbuz, Demirci, Yavuz, \& Caykara, 2011; Jiang \& Xu, 2013) and single-electron transferliving radical polymerization (Demirci, Kinali-Demirci, \& Caykara, 2013; Percec et al., 2006). LRP provides excellent control over the molecular weight and polydispersity of graft polymers (Braunecker \& Matyjaszewski, 2007; Dietrich et al., 2010). Among all LRP techniques, RAFT polymerization is the most important one, due to its compatibility with a wide range of monomers and reaction conditions (Chen, Liu, Chen, Gong, \& Gao, 2011; Moad et al., 2010). The stability and chemical versatility inherent in RAFT agents makes RAFT-based procedures highly attractive for the preparation of well-defined polymers with specific polymer architectures (Smith, Holley, \& McCormick, 2011).

The electrospun nanofibrous webs have shown great potential to be used as affinity membranes for separate/capture macromolecules, microorganism, enzymes, heavy metal ions and waste compounds (Che, Huang, \& Xu, 2011; Lu \& Hsieh, 2009; Ma et al., 2005; Wang et al., 2011; Zhang et al., 2010). For example, Zhang et al. (2010) presented a new affinity membrane which was surface modified electrospun polyacrylonitrile nanofibers for bromelain adsorption. Che et al. (2011) reported that glycosylated nanofibrous membrane showed strong selectivity, high adsorption capacity and reversible binding capability to the specific protein concanavalin A. DNA is the genetic material of living organisms, and determination of DNA plays an important role in many applications ranging from medical, forensic, agriculture and food sciences (Tao, Lin, Huang, Ren, \& Qu, 2012). Different solid supports have been used for adsorption of DNA due to the ease of handling, and less chemical requirements. Wan et al. (2013) reported that a novel electrochemical DNA sensor based on surface initiated enzymatic polymerization. This DNA sensor had picomolar sensitivity and broad detection range. Efficient method for multiple DNA detection by exploring silver nanoclusters and graphene oxide nanohybrid materials was developed by Tao et al. (2012). In our previous study, we also showed that cationic polymer brushes can be used for quantitative DNA adsorption (Demirci \& Caykara, 2013). But, all of these materials, especially polymer coated solid surfaces have low adsorption capacity, because of the low surface area (Baser, Demirel, \& Caykara, 2011; Rahman \& Alaissari, 2011).

Herein, poly[(ar-vinylbenzyl)trimethylammonium chloride] [poly(VBTAC)] grafted cellulose acetate (poly(VBTAC)-g-CA) nanofiber were successfully produced by combination of electrospinning and RAFT polymerization with the goal of fabricating affinity membrane for DNA adsorption. Morphological and surface characteristics of the poly(VBTAC)-g-CA nanofibers were carried out by scanning electron microscope (SEM), Attenuated total reflectance-Fourier transform infrared (ATR-FTIR) spectroscopy, Xray photoelectron spectroscopy (XPS) and contact angle measurements. Furthermore, DNA adsorption of poly(VBTAC)-g-CA nanofibrous web from the buffer solution was investigated. The reusability of poly(VBTAC)-g-CA nanofibrous web was also tested by measuring the adsorption capacity for target DNA after five cycles.

\section{Materials and methods}

\subsection{Materials}

Cellulose acetate (CA, $M_{\mathrm{w}} \sim 30,000,39.8 \mathrm{wt} . \%$ acetyl), (arvinylbenzyl)trimethylammonium chloride (VBTAC, 99\%), 4,4'azobis(4-cyanopentanoic acid) (ACPA, $\geq 98 \%$ ), benzyl chloride (99\%), sulfur ( $\geq 99.5 \%)$, potassium ferricyanide(III) (99\%), N,N'dicyclohexylcarbodiimide (DCC, 99\%), 4-dimethylaminopyridine (DMAP, $\geq 99 \%$ ), acetic acid (99.7\%), sodium acetate ( $\geq 99 \%)$, diethyl ether ( $\geq 99 \%$ ), dichloromethane (DCM, 98.5\%), ethyl acetate (99.8\%), methanol (99.8\%) were purchased commercially from
Sigma-Aldrich. ACPA was recrystallized from methanol. The water was used from a Millipore Milli-Q ultrapure water system. Doublestranded DNA (Cy3-labeled DNA) of 50 base pair from BioVentures Inc. was supplied.

\subsection{Electrospinning}

The homogenous electrospinning solution was prepared by dissolving CA in DCM/methanol $(4 / 1(\mathrm{v} / \mathrm{v}))$ binary solvent mixture at $12 \%(\mathrm{w} / \mathrm{v})$ polymer concentration. Then clear CA solution was placed in a $3 \mathrm{~mL}$ syringe fitted with a metallic needle of $0.6 \mathrm{~mm}$ inner diameter. The syringe was fixed horizontally on the syringe pump (KD Scientific). The electrode of the high-voltage power supply (Matsusada Precision, AU Series) was clamped to the metal needle tip, and the cylindrical aluminum collector was grounded. The parameters of the electrospinning were adjusted as; feed rate of solutions $=1 \mathrm{~mL} / \mathrm{h}$, the applied voltage $=15 \mathrm{kV}$, and the tip-tocollector distance $=10 \mathrm{~cm}$. Electrospun nanofibers were deposited on a grounded stationary cylindrical metal collector covered with a piece of aluminum foil. The electrospinning apparatus was enclosed in a Plexiglas box, and electrospinning was carried out at $25^{\circ} \mathrm{C}$ at $25 \%$ relative humidity. The collected nanofibers were dried at room temperature under the fume hood overnight.

\subsection{RAFT polymerization of VBTAC}

4-Cyanopentanoic acid dithiobenzoate (CPAD) was synthesized according to the literature procedure (Mayadunne et al., 1999). $\operatorname{CPAD}(1.14 \mathrm{~g}, 4.095 \mathrm{mmol}), \mathrm{DCC}(0.844 \mathrm{~g}, 4.095 \mathrm{mmol}), \operatorname{DMAP}(0.5 \mathrm{~g}$, $4.095 \mathrm{mmol}$ ), and $10 \mathrm{~mL}$ of benzene were added to a round bottomed flask and stirred for few minutes under nitrogen atmosphere. The CA nanofibers were added, and the mixture was stirred overnight at room temperature. The product was washed with benzene, 2-propanol and water several times and dried.

The RAFT-mediated polymerization of VBTAC $(29.4 \mathrm{mmol})$ was carried out in buffer $(28 \mathrm{~mL}, \mathrm{pH}=5.0,0.27 \mathrm{~mol} / \mathrm{L}$ acetic acid, and $0.73 \mathrm{~mol} / \mathrm{L}$ sodium acetate), initiator ACPA $(0.025 \mathrm{mmol})$, free RAFT agent CPAD $(0.125 \mathrm{mmol})$, and RAFT chain transfer agent immobilized CA nanofiber at $0{ }^{\circ} \mathrm{C}$ in a round-bottom flask. To ensure smooth stirring and prevent damage to the nanofibers, we isolated the magnetic stirring bar at the center of device from the slides by a $1 \mathrm{~cm}$ high glass $\mathrm{O}$-ring. The solution was diluted to $30 \mathrm{~mL}$ volume with the buffer solution and degassed by purging with nitrogen for $20 \mathrm{~min}$. The polymerization reaction was stirred vigorously at $70{ }^{\circ} \mathrm{C}$ for $120 \mathrm{~min}$. The poly(VBTAC)-g-CA nanofibers were recovered from the reaction mixture and repeatedly washed with buffer and water to remove the unreacted chemicals, and dried under vacuum at $30^{\circ} \mathrm{C}$.

\subsection{Measurements and characterization}

Attenuated total reflectance-Fourier transform infrared (ATRFTIR) spectra of the CA and poly(VBTAC)-g-CA were obtained using a Thermo Nicolet 6700 spectrometer with a Smart Orbit attenuated total reflection attachment. The spectra were taken at a resolution $4 \mathrm{~cm}^{-1}$ after 128 scan accumulation for an acceptable signal/noise ratio. The X-ray photoelectron spectra of samples were recorded by using X-ray photoelectron spectrometer (XPS) (Thermo Scientific). XPS was used by means of a flood gun charge neutralizer system equipped with a monochromated Al K- $\alpha$ Xray source ( $h v=1486.6 \mathrm{eV}$ ). Charging neutralizing equipment was used to compensate sample charging, and the binding scale was referenced to the aliphatic component of $C 1 \mathrm{~s}$ spectra at $285.0 \mathrm{eV}$. The morphologies of the electrospun CA and poly(VBTAC)-gCA nanofibers were investigated with a field emission scanning electron microscope (FE-SEM) (FEI, Quanta 200 FEG). Samples were 


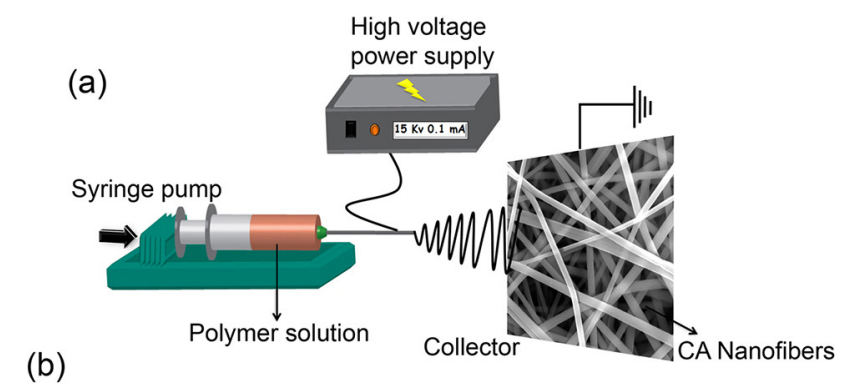

(b)

(a)

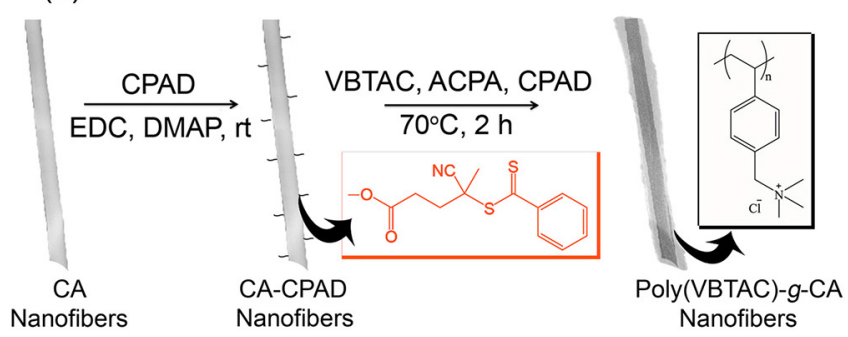

(c)

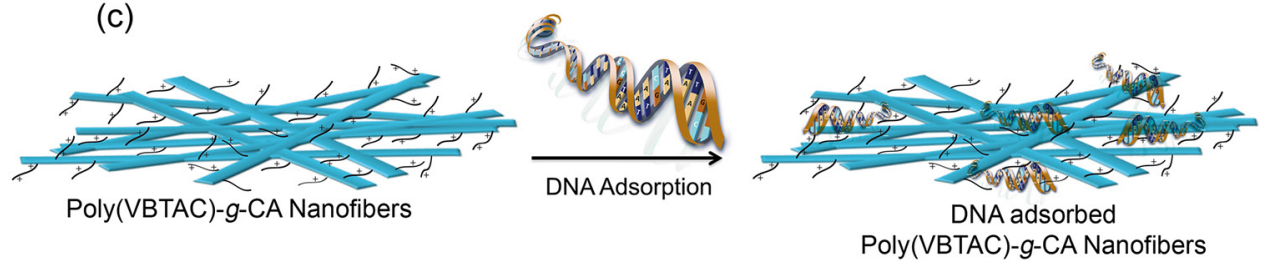

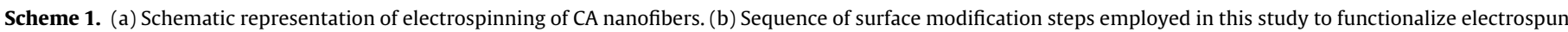
CA nanofibers with poly(VBTAC). (c) DNA adsorption on poly(VBTAC)-g-CA nanofibers.

sputtered with $5 \mathrm{~nm} \mathrm{Au/Pd} \mathrm{(PECS-682)} \mathrm{and} \mathrm{around} 100$ fiber diameters were measured from the SEM images to calculate the average fiber diameter of each sample. The water contact angle measurements were conducted at room temperature using a goniometer (DSA 100, Krüss) equipped with a microliter syringe. Deionized water ( $5 \mu \mathrm{L}, 18 \mathrm{M} \Omega \mathrm{cm}$ resistivity) was used as the wetting liquid. Evidence of the nonspecific adsorption was obtained by means of optical fluorescence microscopy. Fluorescence microscopy images were recorded by using an Olympus BX51 microscope with a $40 \times$ objective.

\subsection{DNA adsorption study}

DNA solution was prepared in an aqueous solution of phosphate buffer saline (PBS). The adsorption of DNA onto poly(VBTAC)$g$-CA nanofibers was performed in a $3.0 \mathrm{~mL}$ volume. $10 \mathrm{mg}$ of poly(VBTAC)-g-CA nanofibers was added to $2.0 \mathrm{~mL}$ DNA $(20.0 \mu \mathrm{g} / \mathrm{mL})$ containing buffer solution (i.e. adsorption medium). At the end of the incubation time, poly(VBTAC)-g-CA nanofibers were separated quickly. The DNA concentration was determined by measuring the absorbance at $260 \mathrm{~nm}$ in a UV-vis spectrophotometer using a standard calibration curve. All of the absorbance values were measured at least three times and averaged. The amount of DNA adsorbed onto the poly(VBTAC)-g-CA nanofibers ( $\mu \mathrm{g}$ DNA/mg dry nanofibers) was calculated from the initial and final DNA concentrations in the clear phase. An average result of minimum three reproducible data was considered allowing errors in $\pm 0.05 \mu \mathrm{g} / \mathrm{mg}$ poly(VBTAC)-g-CA nanofibers. In order to test the reusability of poly(VBTAC)-g-CA nanofibers for DNA adsorption, five cycles of adsorption/desorption were carried out using buffer solution (potassium hydrogen phthalate/hydrochloric acid, $\mathrm{pH}=3.0$ ). After each adsorption/desorption cycle, DNA concentration was determined by UV-vis spectrophotometer. In order to use the poly(VBTAC)- $g$-CA nanofibers for the next experiment, it was washed with buffer solution and distilled water, sequentially.

\section{Results and discussion}

\subsection{Formation poly $(V B T A C)$ grafted $C A$ nanofibers}

An illustration of immobilization of RAFT agent onto CA nanofibers and subsequent RAFT polymerization to form cationic poly(VBTAC) brushes and DNA adsorption is shown in Scheme 1. The poly(VBTAC)-g-CA nanofibers were prepared via three-step process involving; (i) electrospinning of CA nanofibers, (ii) coupling of RAFT agent to the electrospun CA nanofiber surface via esterification reaction of non-acetylated $-\mathrm{OH}$ groups of $\mathrm{CA}$ with CPAD, (iii) surface initiated RAFT polymerization of VBTAC. Fig. 1 shows the FTIR spectra of untreated CA nanofibers and CPAD immobilized CA (CPAD-CA) nanofibers. The characteristic band of the $39.8 \%$ acetyl CA was observed at 1737,1220 and $1034 \mathrm{~cm}^{-1}$ due to the $\mathrm{C}=\mathrm{O}$, asymmetric and symmetric $\mathrm{C}-\mathrm{O}$ stretching, respectively (Celebioglu, Demirci, \& Uyar, 2014). The band area of the C-O group increased with esterification reaction. ATR-FTIR spectrum of CACPAD nanofibers also showed absorbance band at $2246 \mathrm{~cm}^{-1}$ for the $-\mathrm{C} \equiv \mathrm{N}$ and $1040 \mathrm{~cm}^{-1}$ for the $\mathrm{C}=\mathrm{S}$ stretching. $\mathrm{CPAD}-\mathrm{CA}$ nanofibers have higher absorbance than CA nanofibers. The characteristic band of $C A$ was observed at $1739 \mathrm{~cm}^{-1}$ due to the $C=O$ stretching. On the other hand, the bands of poly(VBTAC) appeared at $1481 \mathrm{~cm}^{-1}$ for the scissor $-\mathrm{CH}_{2}-$ vibration, at $1403 \mathrm{~cm}^{-1}$ asymmetric $-\mathrm{CH}_{3}$ deformation vibration and at $1610 \mathrm{~cm}^{-1}-\mathrm{C}-\mathrm{C}-$ stretches of the aromatic ring (Demirci \& Caykara, 2012). The spectrum of the poly(VBTAC)-g-CA nanofibers was characterized by the presence of the absorption bands typical of the pure components., with the intensity roughly proportional to grafting ratio.

The chemical composition of the poly(VBTAC)-g-CA nanofibers was determined by XPS (Table 1, Fig. 2). The core level XPS spectra of CPAD overlayer consist of $\mathrm{N} 1 \mathrm{~s}$ and $\mathrm{C} 1 \mathrm{~s}$ peaks curve fitted into the components with binding energies at about $400.1 \mathrm{eV}(\mathrm{N} \equiv \mathrm{C})$ for $\mathrm{N} 1 \mathrm{~s}$ and $289.1 \mathrm{eV}(\mathrm{C}=\mathrm{O}), 287.9 \mathrm{eV}(\mathrm{O}-\underline{\mathrm{C}}-\mathrm{O}), 286.0 \mathrm{eV}(\underline{\mathrm{C}}-\mathrm{N})$, $285.4 \mathrm{eV}(\underline{\mathrm{C}}-\mathrm{S})$, and $285.0 \mathrm{eV}(\underline{\mathrm{C}}-\mathrm{C} / \underline{\mathrm{C}}-\mathrm{H})$ for $\mathrm{C} 1 \mathrm{~s}$ (Table 1, Fig. 2). 
Table 1

Atomic concentration and binding energies given high resolution XPS for nanofibers ${ }^{\mathrm{a}}$.

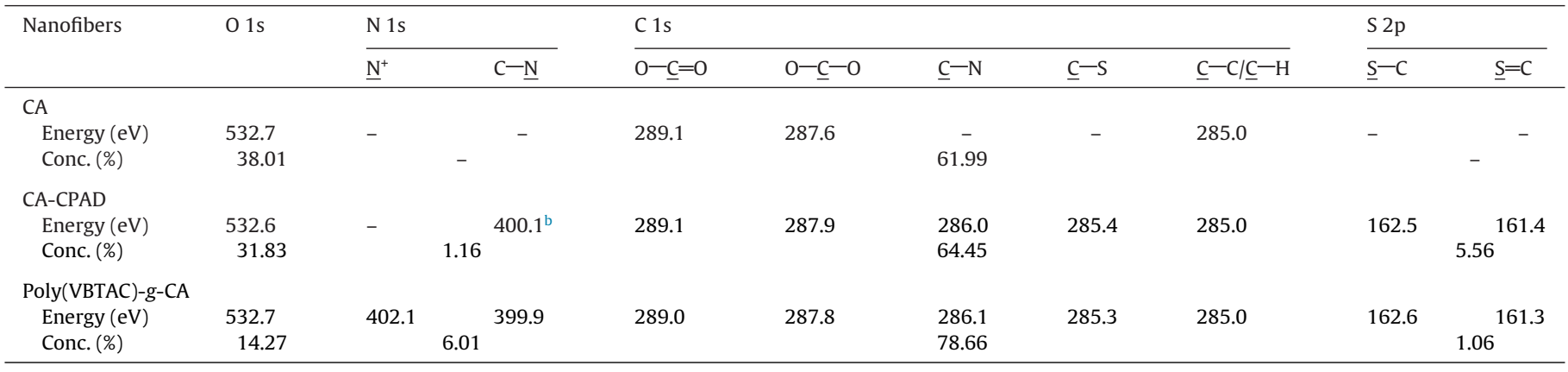

a Binding energies are calibrated to aliphatic carbon at $285.0 \mathrm{eV}$.

b Binding energy attributable to the $\mathrm{C} \equiv \mathrm{N}$ species.

The immobilization of CPAD onto CA nanofiber was also confirmed from the appearance of a $S 2 p$ peak curve fitted into two components with binding energies at about $162.5 \mathrm{eV}(\mathrm{C}-\mathrm{S})$ and $161.4 \mathrm{eV}$ $(\mathrm{C}=\mathrm{S})$. Overall, the ATR-FTIR and XPS studies confirmed the successful coupling of the RAFT agent (CPAD) onto electrospun CA nanofibers surface. The core level XPS spectra of nanofibers consist of $\mathrm{N} 1 \mathrm{~s}$ and $\mathrm{C} 1 \mathrm{~s}$ peaks curve fitted into the components with binding energies at about $402.1 \mathrm{eV}\left(\mathrm{C}-\mathrm{N}^{+}\right)$and $399.9 \mathrm{eV}(\mathrm{C}-\mathrm{N})$ for $\mathrm{N}$ $1 \mathrm{~s}$ and $289.0 \mathrm{eV}(\underline{\mathrm{C}}=\mathrm{O}), 287.8 \mathrm{eV}(\mathrm{O}-\underline{\mathrm{C}}-\mathrm{O}), 286.1 \mathrm{eV}(\underline{\mathrm{C}}-\mathrm{N}), 285.3 \mathrm{eV}$ $(\underline{\mathrm{C}}-\mathrm{S})$ and $285.0 \mathrm{eV}(\underline{\mathrm{C}}-\mathrm{C} / \underline{\mathrm{C}}-\mathrm{H})$ for $\mathrm{C} 1 \mathrm{~s}$.

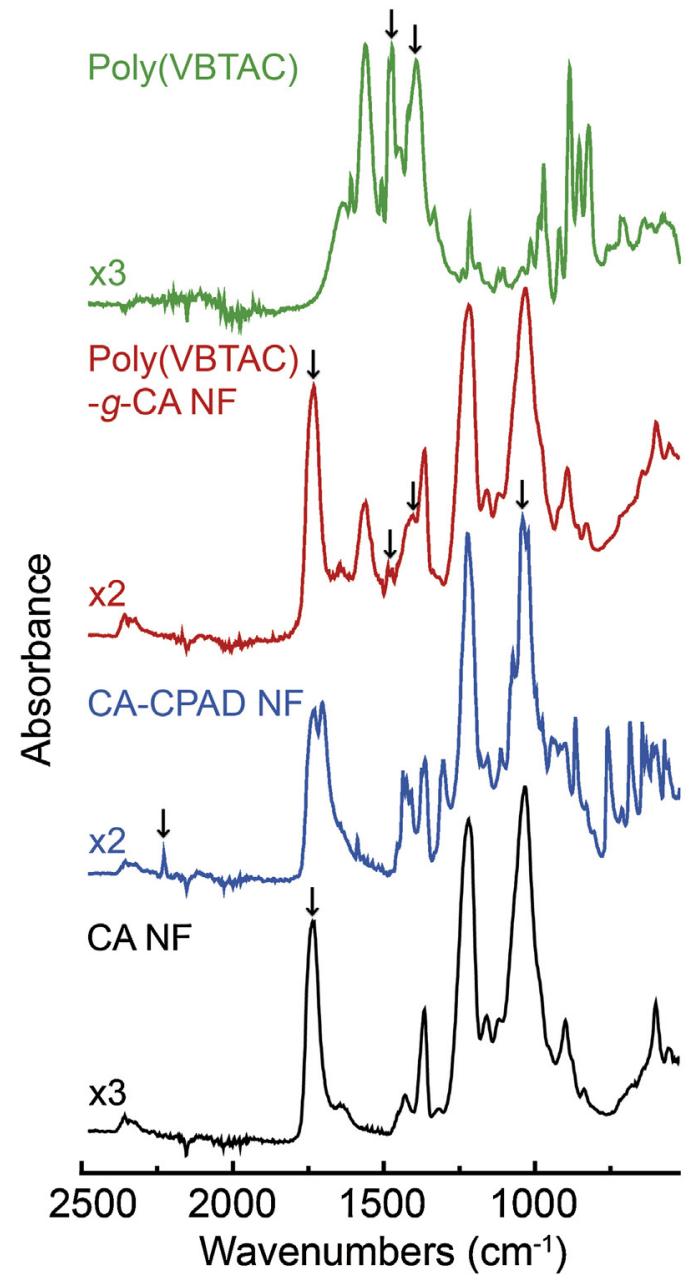

Fig. 1. FTIR spectra of $C A$ nanofibers, $C A-C P A D$ nanofibers, poly(VBTAC)-g-CA nanofibers and poly(VBTAC).
The static water contact angle of CPAD functionalized CA nanofiber was $62 \pm 3^{\circ}$ which was lower than the value of $88 \pm 2^{\circ}$ for the CA nanofiber before the immobilization (Table 2). When the CA nanofibers were grafted with poly(VBTAC), the static water contact angle of the surface decreased substantially to about $39 \pm 4^{\circ}$, consistent with the hydrophilic nature of poly(VBTAC).

Fig. 3 shows the representative SEM images of the CA and poly(VBTAC)-g-CA nanofibers. The SEM imaging showed that the electrospun CA nanofibers were bead free and smooth morphology having average fiber diameter (AFD) of $810 \pm 260 \mathrm{~nm}$ (Fig. 3a). It should be noted that surface morphologies and average

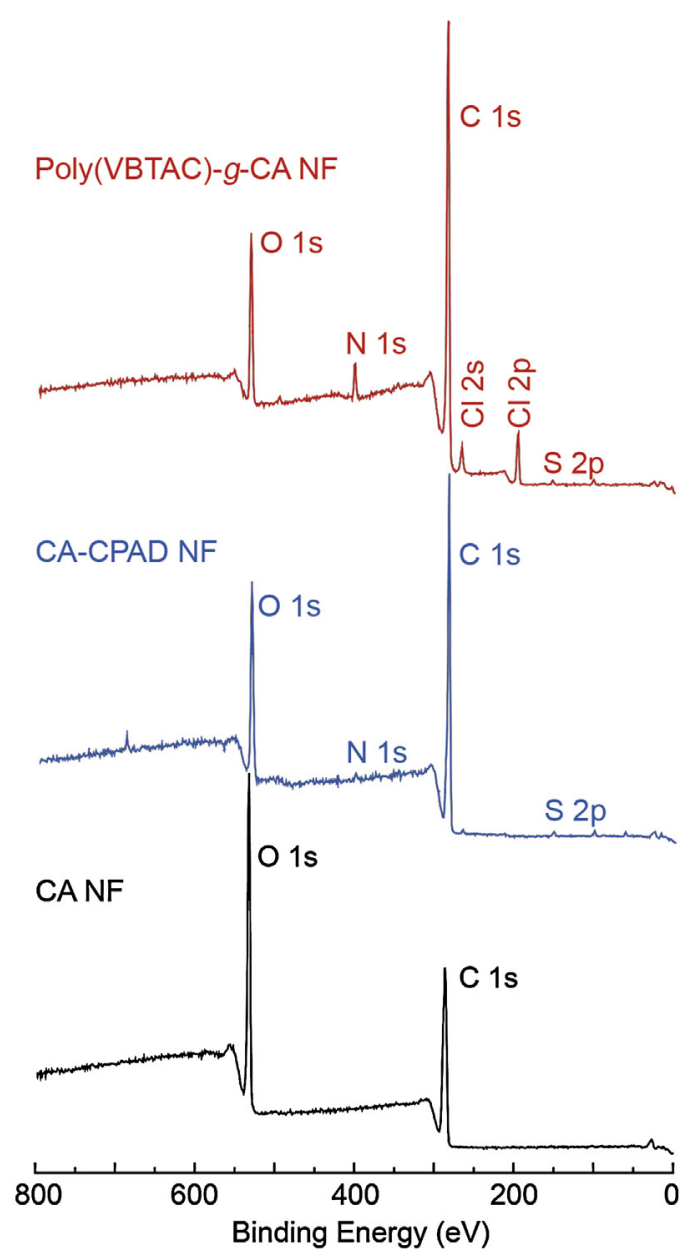

Fig. 2. XPS survey scan spectra of $C A$ nanofibers, CA-CPAD nanofibers and poly(VBTAC)-g-CA nanofibers. 

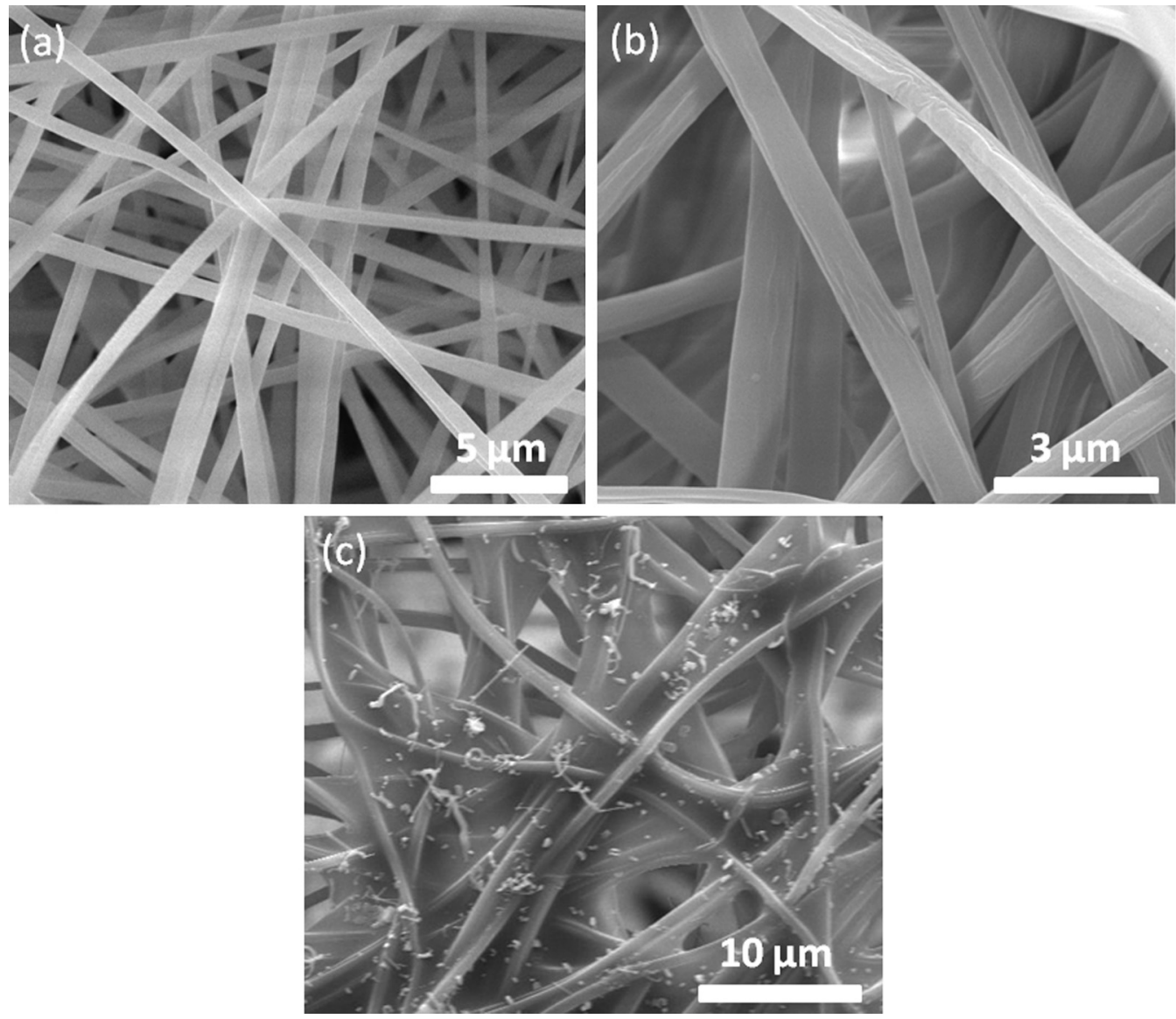

Fig. 3. SEM images of CA nanofibers (a), poly(VBTAC)-g-CA nanofibers (b) and DNA adsorbed poly(VBTAC)-g-CA nanofibers (c).

fiber diameter of poly(VBTAC)-g-CA nanofibers were different from the CA nanofibers. That is, the smooth appearance of CA nanofiber surface was no longer present (Fig. $3 \mathrm{~b}$ ) due to the poly(VBTAC) grafting. Additionally, poly(VBTAC)-g-CA nanofibers were slightly thicker having AFD of $1030 \pm 310 \mathrm{~nm}$ when compared to pure CA nanofibers because of the poly(VBTAC) coating as well as possible swelling of nanofibers during grafting process. These changes in the surface appearance of the poly(VBTAC)-g-CA nanofibers are the physical evidences for the successful grafting reaction.

\subsection{Adsorption of DNA}

DNA molecules are likely immobilized onto the cationic surfaces by electrostatic interaction between negatively charged

Table 2

Static water contact angle and photographs of $5 \mu \mathrm{L}$ water droplets for nanofibers.

\begin{tabular}{lll}
\hline Nanofibers & Contact angle $\left(^{\circ}\right)$ & Image \\
\hline CA & $88 \pm 2$ \\
CA-CPAD & $62 \pm 3$ \\
PVBTAC-g-CA & $39 \pm 4$
\end{tabular}

DNA and positively charged polymer surface. Adsorption of DNA onto the CA and poly(VBTAC)-g-CA nanofibrous web was provided fluorescence microscopy. As it can be seen in Fig. 4, the red spots indicated the presence of DNA molecules. The adsorption kinetics of DNA was performed at $20^{\circ} \mathrm{C}$. The pristine CA nanofibrous web was used as a reference material. The result shown in Fig. 5a indicates that there is no significant effect of incubation time on the adsorption of DNA onto the poly(VBTAC)g-CA nanofibers. The adsorbed amount of DNA almost reaches a plateau after $90 \mathrm{~min}$. This behavior can be explained due to the rapid and strong electrostatic attraction between cationic poly(VBTAC)-g-CA nanofibers and anionic DNA molecules, and very high surface area to volume ratio of nanofibrous web, so the equilibrium concentration of adsorbed DNA is reached very quickly. The maximum DNA adsorption capacity was $2.4 \mu \mathrm{g} / \mathrm{mg}$ for the pristine CA web and $26.6 \mu \mathrm{g} / \mathrm{mg}$ for the poly(VBTAC)-g-CA web. These results indicated that the grafting of poly(VBTAC) on CA nanofibers provided a significant increase in the DNA adsorption capacity. Fig. 3c shows the SEM images of the poly(VBTAC)-g-CA nanofibers after DNA adsorption in which the DNA adsorption on the poly(VBTAC)-g-CA nanofibers was observed microscopically.

The adsorption isotherms represent the relationship between the amount adsorbed by a unit weight of adsorbent and the amount of adsorbate remaining in the solution at equilibrium. Fig. 5b shows the dependence of the adsorption of DNA on the poly(VBTAC)-g-CA nanofibrous web on the equilibrium DNA concentration. The initial concentration of DNA in the adsorption medium was changed between 10 and $100 \mu \mathrm{g} / \mathrm{mL}$. The Langmuir isotherm model assumes a monolayer adsorption onto a surface containing a finite number of adsorption sites of uniform strategies of adsorption with no 

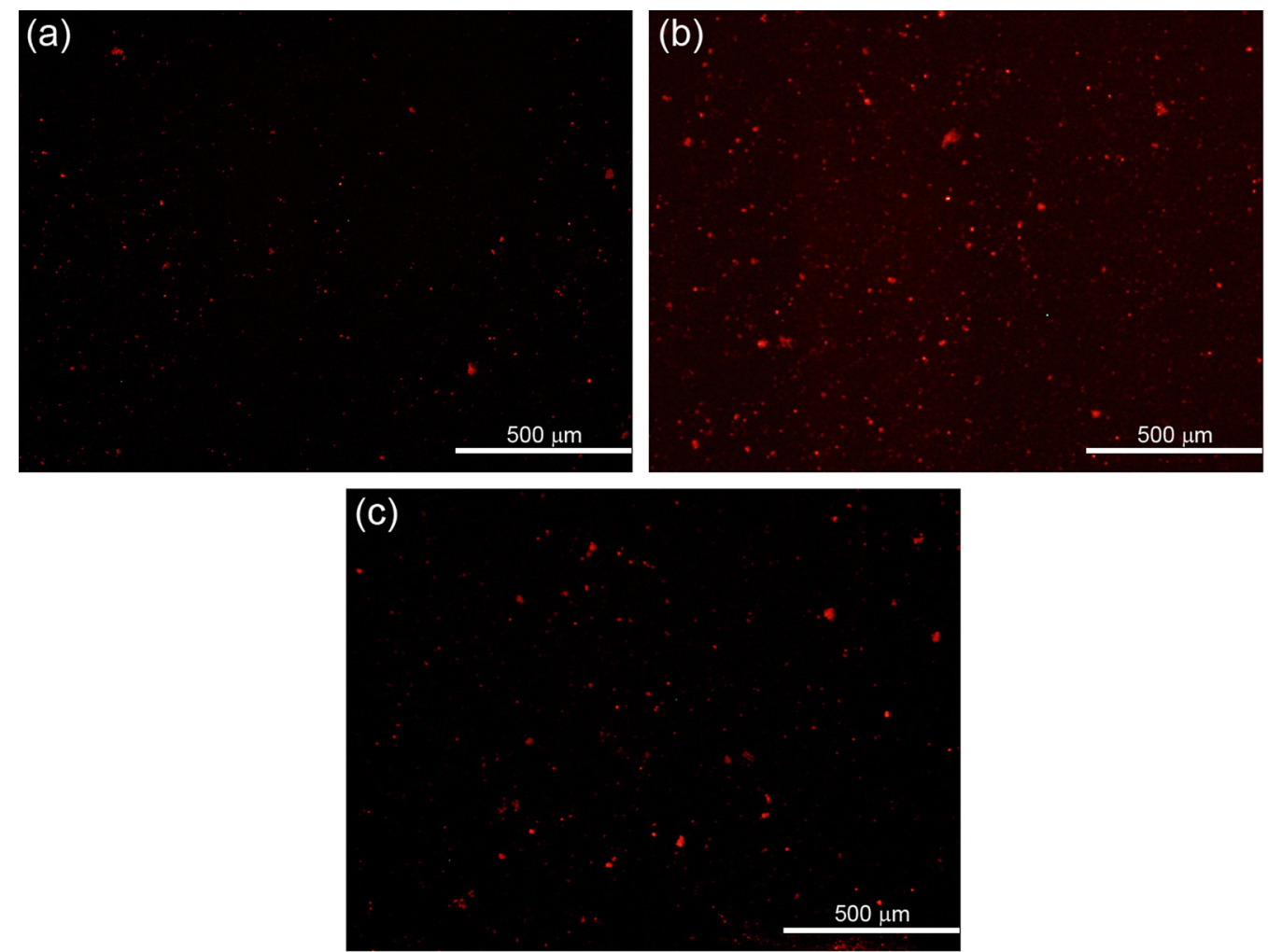

Fig. 4. Fluorescence microscopy images of CA nanofibers (a), poly(VBTAC)-g-CA nanofibers (b) and poly(VBTAC)-g-CA nanofibers after desorption procedure (c).

transmigration of adsorbate in the plane of surface, and it is given by the following equation:

$\frac{C_{e}}{q_{e}}=\frac{1}{q_{m} K_{m}}+\frac{C_{e}}{q_{m}}$

where $C_{e}(\mu \mathrm{g} / \mathrm{mL})$ is the equilibrium concentration of DNA solution, $q_{e}(\mu \mathrm{g} / \mathrm{mg})$ is the equilibrium amount of DNA adsorbed, $q_{m}(\mu \mathrm{g} / \mathrm{mg})$ is the maximum amount of DNA adsorbed per unit mass of nanofiber, and $K_{m}(\mathrm{~mL} / \mathrm{mg})$ is a constant related to the adsorption. As illustrated in Fig. 5b, a linear plot with correlation coefficient $\left(R^{2}\right)$ value of 0.973 was obtained from Langmuir isotherm equation when plotting $C_{e} / q_{e}$ against $C_{e}$ with a slope and intercept equal to $1 / q_{m}$ and $1 / K_{m} q_{m}$, respectively. Kinetic parameters were calculated as $2.52 \times 10^{-2} \mathrm{~mL} / \mu \mathrm{g}$ for $K_{m}$ and $23.51 \mu \mathrm{g} / \mathrm{mg}$ for $q_{m}$. Moreover, the Langmuir equation fits well for DNA immobilization on the poly(VBTAC)-g-CA web under the concentration
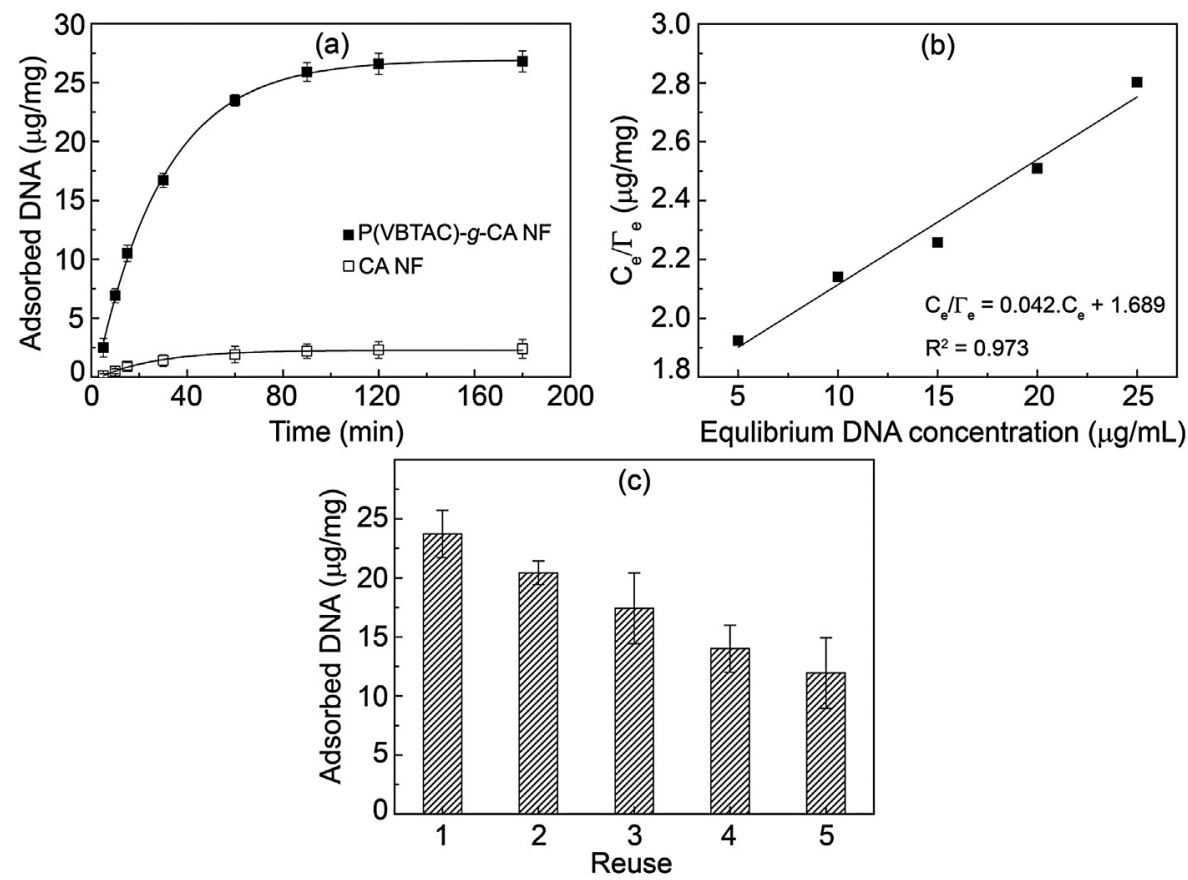

Fig. 5. Adsorption kinetics (a), adsorption isotherm (b) and reusability (c) of poly(VBTAC)-g-CA nanofibers. 
range studied. Adsorption capacity of some solid surfaces was previously investigated as detailed elsewhere (Baser et al., 2011; Demirci et al., 2013; Rahman \& Alaissari, 2011). Compared to solid surfaces, poly(VBTAC)-g-CA nanofibrous web showed higher adsorption capacity.

The essential feature of the Langmuir isotherm can be expressed by means of a dimensionless constant separation factor or equilibrium parameter $\left(R_{L}\right) . R_{L}$ is calculated using the following equation:

$R_{L}=\frac{1}{1+K_{m} C_{0}}$

where $K_{m}$ is the Langmuir constant which indicates the nature of adsorption and the shape of the isotherm, and $C_{0}$ refers to the initial DNA concentration $(\mu \mathrm{g} / \mathrm{mL})$. The parameter $R_{L}>1, R_{L}=1,0<R_{L}<1$, $R_{L}=0$ indicates the isotherm shape according to unfavorable, linear, favorable and irreversible, respectively (Demirci et al., 2013; Kim, Barraza, \& Velev, 2009; Mallampati \& Valiyaveettil, 2012). The $R_{L}$ values of DNA adsorption on poly(VBTAC)-g-CA nanofibers were given in Table S1 (Supplementary data). The $R_{L}$ values confirmed that the adsorption is favorable under conditions used in this study.

The reusability of poly(VBTAC)-g-CA nanofibrous web was investigated by measuring the adsorption capacity for target DNA in a cyclic manner. The adsorption/desorption procedures were repeated five times to verify the reusability of the web. The cycles of adsorption/desorption processes are shown in Fig. 5c. Drastic decrease (approximately $11.5 \%$ ) in the adsorption capacity was seen during the each cycle, and the poly(VBTAC)-g-CA nanofibers retained DNA an uptake capacity of $\sim 46 \%$ after five cycles. Fig. S1 (Supplementary data) shows the XPS survey spectra of the poly(VBTAC)-g-CA nanofibers after adsorption and desorption procedure. As can be seen from Fig. S1b(Supplementary data), intensity of the P 2p peak at $133 \mathrm{eV}$ decreased. However, unfortunately $P$ 2p peak and fluorescence signal (Fig. 4c) of poly(VBTAC)-gCA nanofibers did not disappear completely. Our previous study clearly demonstrate that poly(VBTAC) polymer brushes are cationic behavior at different pHs (Demirci \& Caykara, 2013). On the other hand, DNA is negatively charged due to the phosphate groups on its backbone, and with decreasing $\mathrm{pH}$ these negative phosphate groups become protonated and DNA molecule turns less negative. This is due to electrostatic interaction between poly(VBTAC)- $g$-CA nanofibers and less negative DNA molecules $(\mathrm{pH}=3.0)$ and it was evident that our washing procedure did not able to remove all the adsorbed DNA. Because of this, the adsorption capacity of DNA was decreased from 23.51 to $12.64 \mu \mathrm{g} / \mathrm{mg}$ with increasing number of reuse.

\section{Conclusions}

In conclusion, cationic poly(VBTAC)-g-CA nanofibers were manufactured via combination of electrospinning and RAFT polymerization techniques with the goal of the adsorption of DNA. Our systematic studies by using techniques such as ATR-FTIR and XPS confirmed the successful grafting of poly(VBTAC) on electrospun CA nanofibers. The SEM imaging showed that the electrospun CA nanofibers were bead free and smooth morphology. However, surface morphologies and average fiber diameter of poly(VBTAC)$g$-CA nanofibers were different from the CA nanofibers. These changes in the surface appearance of the poly(VBTAC)-g-CA nanofibers are the physical evidences for the successful grafting reaction. The static water contact angle of the nanofibers decreased from $88 \pm 2$ to $39 \pm 4^{\circ}$, consistent with the hydrophilic nature of poly(VBTAC). The DNA adsorption capacity was determined as $23.51 \mu \mathrm{g} / \mathrm{mg}$ from the Langmuir isotherm for poly(VBTAC)-g-CA nanofibrous web. We have also demonstrated the reusability of the poly(VBTAC)-g-CA web by measuring the adsorption capacity for target DNA in a cyclic manner. Our studies have shown that poly(VBTAC)-g-CA nanofibers presents a convenient approach for DNA immobilization. The results reported in this article could open up new opportunities for fabricating surface functionalized electrospun nanofibers/nanowebs and their applications in biotechnological uses.

\section{Acknowledgements}

Dr T. Uyar acknowledges EU FP7-PEOPLE-2009-RG Marie Curie-IRG (NANOWEB, PIRG06-GA-2009-256428) and The Turkish Academy of Sciences - Outstanding Young Scientists Award Program (TUBA-GEBIP) for partial funding. A. Celebioglu acknowledges TUBITAK-BIDEB for the national PhD study scholarship.

\section{Appendix A. Supplementary data}

Supplementary data associated with this article can be found, in the online version, at http://dx.doi.org/10.1016/ j.carbpol.2014.06.086.

\section{References}

Agarwal, S., Greiner, A., \& Wendorff, J. H. (2013). Functional materials by electrospinning of polymers. Progress in Polymer Science, 38(6), 963-991.

Bai, L., Zhang, L., Cheng, Z., \& Zhu, X. (2012). Activators generated by electron transfer for atom transfer radical polymerization: Recent advances in catalyst and polymer chemistry. Polymer Chemistry, 3(10), 2685-2697.

Baser, B., Demirel, G., \& Caykara, T. (2011). DNA adsorption on poly $(\mathrm{N}, \mathrm{N}-$ dimethylacrylamide)-grafted chitosan hydrogels. Journal of Applied Polymer Science, 120(3), 1420-1425.

Bian, K., \& Cunningham, M. F. (2006). Surface-initiated nitroxide-mediated radical polymerization of 2-(dimethylamino)ethyl acrylate on polymeric microspheres. Polymer, 47(16), 5744-5753.

Braunecker, W. A., \& Matyjaszewski, K. (2007). Controlled/living radical polymerization: Features, developments, and perspectives. Progress in Polymer Science, 32(1), 93-146.

Celebioglu, A., Demirci, S., \& Uyar, T. (2014). Cyclodextrin-grafted electrospun cellulose acetate nanofibers via click reaction for removal of phenanthrene. Applied Surface Science, 305, 581-588.

Che, A. F., Huang, X. J., \& Xu, Z. K. (2011). Polyacrylonitrile-based nanofibrous membrane with glycosylated surface for lectin affinity adsorption. Journal of Membrane Science, 366(1-2), 272-277.

Chen, J., Liu, M., Chen, C., Gong, H., \& Gao, C. (2011). Synthesis and characterization of silica nanoparticles with well-defined thermoresponsive pnipam via a combination of raft and click chemistry. ACS Applied Materials E' Interfaces, 3(8), 3215-3223.

Chigome, S., Darko, G., \& Torto, N. (2011). Electrospun nanofibers as sorbent material for solid phase extraction. Analyst, 136(14), 2879-2889.

Cimen, D., \& Caykara, T. (2012). Biofunctional oligoN-isopropylacrylamide brushes on silicon wafer surface. Journal of Materials Chemistry, 22(26), 13231-13238.

Coessen, V., Pintauer, T., \& Matyjaszewski, K. (2001). Functional polymers by atom transfer radical polymerization. Progress in Polymer Science, 26(3), 337-377.

Demirci, S., \& Caykara, T. (2012). Controlled grafting of cationic poly[(arvinylbenzyl)trimethylammonium chloride] on hydrogen-terminated silicon substrate by surface-initiated RAFT polymerization. Reactive and Functional Polymers, 72(9), 588-595.

Demirci, S., \& Caykara, T. (2013). RAFT-mediated synthesis of cationic poly[(arvinylbenzyl)trimethyl ammonium chloride] brushes for quantitative DNA immobilization. Materials Science and Engineering C, 33(1), 111-120.

Demirci, S., Kinali-Demirci, S., \& Caykara, T. (2013). Stimuli-responsive diblock copolymer brushes via combination of click chemistry and living radical polymerization. Journal of Polymer Science Part A: Polymer Chemistry, 51(12) 2677-2685

Dietrich, M., Glassner, M., Gruendling, T., Schmid, C., Falkenhagen, J., \& BarnerKowollik, C. (2010). Facile conversion of RAFT polymers into hydroxyl functional polymers: A detailed investigation of variable monomer and RAFT agent combinations. Polymer Chemistry, 1(5), 634-644.

Fu, G. D., Xu, L. Q., Yao, F., Li, G. L., \& Kang, E. T. (2009). Smart nanofibers with a photoresponsive surface for controlled release. ACS Applied Materials E Interfaces 1(11), 2424-2427.

Fu, G. D., Xu, L. Q., Yao, F., Zhang, K., Wang, X. F., Zhu, M. F., et al. (2009). Smart nanofibers from combined living radical polymerization, click chemistry, and electrospinning. ACS Applied Materials E' Interfaces, 1(2), 239-243.

Gurbuz, N., Demirci, S., Yavuz, S., \& Caykara, T. (2011). Synthesis of cationic $\mathrm{N}$-[3-(dimethylamino)propyl]methacrylamide brushes on silicon wafer via surface-initiated RAFT polymerization. Journal of Polymer Science Part A: Polymer Chemistry, 49(2), 423-431. 
Jiang, H., \& Xu, F. J. (2013). Biomolecule-functionalized polymer brushes. Chemical Society Reviews, 42(8), 3394-3397.

Kampalanonwat, P., \& Supaphol, P. (2010). Preparation and adsorption behavior of aminated electrospun polyacrylonitrile nanofiber mats for heavy metal ion removal. ACS Applied Materials \& Interfaces, 2(12), 3619-3627.

Kayaci, F., Ozgit-Akgun, C., Biyikli, N., \& Uyar, T. (2013). Surface-decorated ZnO nanoparticles and $\mathrm{ZnO}$ nanocoating on electrospun polymeric nanofibers by atomic layer deposition for flexible photocatalytic nanofibrous membranes. RSC Advances, 3(19), 6817-6820.

Kim, S., Barraza, H., \& Velev, O. D. (2009). Intense and selective coloration of foams stabilized with functionalized particles. Journal of Materials Chemistry, 19(38), 7043-7049.

Lu, P., \& Hsieh, Y.-L. (2009). Lipase bound cellulose nanofibrous membrane via Cibacron Blue F3GA affinity ligand. Journal of Membrane Science, 330(1-2), 288-296.

Lu, P., \& Hsieh, Y.-L. (2010). Multiwalled carbon nanotube (MWCNT) reinforced cellulose fibers by electrospinning. ACS Applied Materials \& Interfaces, 2(8), 2413-2420.

Ma, Z., Kotaki, M., \& Ramakrishna, S. (2005). Electrospun cellulose nanofiber as affinity membrane. Journal of Membrane Science, 265(1-2), 115-127.

Mahanta, N., \& Valiyaveettil, S. (2011). Surface modified electrospun poly(vinyl alcohol) membranes for extracting nanoparticles from water. Nanoscale, 3(11), 4625-4631.

Mallampati, R., \& Valiyaveettil, S. (2012). Application of tomato peel as an efficient adsorbent for water purification-alternative biotechnology? RSC Advances, 2(26), 9914-9920.

Matyjaszewski, K. (2012). General concept and history of living radical polymerization. In K. Matyjaszewski, \& T. P. Davis (Eds.), Handbook of radical polymerization (pp. 361-406). Hoboken: John Wiley \& Sons.

Mayadunne, R. T. A., Rizzardo, E., Chiefari, J., Chong, Y. K., Moad, G., \& Thang, S. H. (1999). Living radical polymerization with reversible addition-fragmentation chain transfer (RAFT polymerization) using dithiocarbamates as chain transfer agents. Macromolecules, 32(21), 6977-6980.

Moad, G., Chen, M., Haussler, M., Postma, A., Rizzardo, E., \& Thang, S. H. (2010). Functional polymers for optoelectronic applications by RAFT polymerization. Polymer Chemistry, 2(3), 492-519.

Muller, D., Rambo, C. R., Porto, L. M., Schreiner, W. H., \& Barra, G. M. O. (2013). Structure and properties of polypyrrole/bacterial cellulose nanocomposites. Carbohydrate Polymers, 94(1), 655-662.

Percec, V., Guliashvili, T., Lasislaw, J. S., Wistrand, A., Stjerndahl, A., Sienkowska, M. J., et al., \& Sahoo, S. (2006). Ultrafast synthesis of ultrahigh molar mass polymers by metal-catalyzed living radical polymerization of acrylates, methacrylates, and vinyl chloride mediated by SET at $25^{\circ} \mathrm{C}$. Journal of the American Chemical Society, 128(43), 14156-14165.
Pyun, J., \& Matyjaszewski, K. (2001). Synthesis of nanocomposite organic/inorganic hybrid materials using controlled/living radical polymerization. Chemistry of Materials, 13(10), 3436-3448.

Rahman, Md. M., \& Alaissari, A. (2011). Temperature and magnetic dual responsive microparticles for DNA separation. Separation and Purification Technology, 81(3), 286-294.

Sahay, R., Kumar, P. S., Sridhar, R., Sundaramurthy, J., Venugopal, J., Mhaisalkar S. G., et al. (2012). Electrospun composite nanofibers and their multifaceted applications. Journal of Materials Chemistry, 22(26), 12953-12971.

Smith, D. D., Holley, A. C., \& McCormick, C. L. (2011). RAFT-synthesized copolymers and conjugates designed for therapeutic delivery of siRNA. Polymer Chemistry, 2(7), 1428-1441.

Tao, Y., Lin, Y., Huang, Z., Ren, J., \& Qu, X. (2012). DNA-templated silver nanoclusters-graphene oxide nanohybrid materials: A platform for label-free and sensitive fluorescence turn-on detection of multiple nucleic acid targets. Analyst, 137(11), 2588-2592.

Turan, E., Demirci, S., \& Caykara, T. (2010). Synthesis of thermoresponsive poly $(N$ isopropylacrylamide) brush on silicon wafer surface via atom transfer radical polymerization. Thin Solid Films, 518(21), 5950-5954.

Uyar, T., Havelund, R., Hacaloglu, J., Besenbacher, F., \& Kingshott, P. (2010). Functional electrospun polystyrene nanofibers incorporating $\alpha-, \beta-$, and $\gamma$ cyclodextrins: Comparison of molecular filter performance. ACS Nano, 4(9), 5121-5130.

Wan, Y., Xu, H., Su, Y., Zhu, X., Song, S., \& Fan, C. (2013). A surface-initiated enzymatic polymerization strategy for electrochemical DNA sensors. Biosensors and Bioelectronics, 41, 526-531.

Wang, S., Zheng, F., Huang, Y., Fang, Y., Shen, M., Zhu, M., et al. (2012). Encapsulation of amoxicillin within laponite-doped poly(lactic-co-glycolic acid) nanofibers: Preparation, characterization, and antibacterial activity. ACS Applied Materials $\mathcal{E}$ Interfaces, 4(11), 6393-6401.

Wang, X., Min, M., Liu, Z., Yang, Y., Zhou, Z., Zhu, M., et al. (2011). Poly(ethyleneimine) nanofibrous affinity membrane fabricated via one step wet-electrospinning from poly(vinyl alcohol)-doped poly(ethyleneimine) solution system and its application. Journal of Membrane Science, 379(1-2), 191-200.

Wendorff, J.H., Agarwal, S., \& Greiner, A. (2012). Electrospinning: materials, processing, and applications. Germany: John Wiley \& Sons.

Yao, F., Xu, L., Lin, B., \& Fu, G. D. (2010). Preparation and applications of functional nanofibers based on the combination of electrospinning, controlled radical polymerization and 'Click Chemistry'. Nanoscale, 2(8), 1348-1357.

Zhang, H., Nie, H., Yu, D., Wu, C., Zhang, Y., White, C. J. B., et al. (2010). Surface modification of electrospun polyacrylonitrile nanofiber towards developing an affinity membrane for bromelain adsorption. Desalination, 256, 141-147.

Zhu, J., Yang, J., \& Sun, G. (2011). Cibacron Blue F3GA functionalized poly(vinyl alcohol-co-ethylene) (PVA-co-PE) nanofibrous membranes as high efficient affinity adsorption materials. Journal of Membrane Science, 385-386, 269-276. 